\title{
Efektivitas Model Reciprocal Teaching dengan Heuristik-KR: Pengaruh Terhadap Kemampuan Representasi dan Self Confidence
}

\author{
Elsa Widya Asri ${ }^{1}$, Achi Rinaldi ${ }^{2}$, Rizki Wahyu Yunian Putra ${ }^{3}$, Nurhasanah Leni ${ }^{4}$, \\ Ahmad Sodiq ${ }^{5}$ \\ 1,2,3,4,5 Universitas Islam Negeri raden Intan Lampung \\ *elsawidyaasri1@gmail.com
}

\begin{tabular}{|l|l|l|l|}
\hline Received : 21-06-2021 & Revised: 01-11-2021 & Accepted: 03-11-2021 & Published: 21-12-2021 \\
\hline
\end{tabular}

\begin{abstract}
ABSTRAK
Penelitian ini bertujuan untuk mengetahui efektivitas penggunaan model pembelajaran reciprocal teaching dengan strategi heuristik krulik rudnick terhadap kemampuan representasi matematika dan self confidence. Jenis eksperimen yang digunakan adalah Quasi Eksperimental. Penelitian ini dilakukan di SMP Negeri 7 Krui. Populasinya adalah peserta didik kelas VIII dan sampel penelitian adalah kelas VIII B dengan jumlah 28 peserta didik sebagai kelas eksperimen dengan menerapkan model pembelajaran reciprocal teaching dengan strategi heuristik krulik rudnick dan kelas VIII A yang jumlah 28 peserta didik sebagai kelas kontrol dengan menerapkan model pembelajaran direct instruction. Teknik pengumpulan data menggunakan tes kemampuan representasi matematika dan angket self confidence. Analisis data menggunkan uji Manova. Hasil analisis data menunjukkan bahwa terdapat pengaruh kemampuan representasi matematika dan self confidence menggunakan model reciprocal teaching dengan strategi heuristik krulik rudnick. Efektivias penggunaan model pembelajaran reciprocal teaching dengan strategi heuristik krulik rudnick lebih efektif terhadap kemampuan representasi matematika dan self confidence, ditunjukkan dari effect size yang diperoleh termasuk dalam kategori tinggi.
\end{abstract}

Kata Kunci : reciprocal teaching, heuristik krulik rudnick, representasi matematika, self confidence

\begin{abstract}
The purpose of this study was to determine the effect of learning reciprocal teaching model with heuristik krulik rudnick strategy on the ability to mathematical representation and self confidence. The type of experiment use is Quasi Experimental. This research was conducted at SMP Negeri 7 Krui. The population was students of class VIII and the research sampel was VIII B consists of 28 students as experiment class with the application of reciprocal teaching model with heuristik krulik rudnick strategy and VIII A consists of 28 students as a control class with the application of direct instruction. Data collection techniques using test of mathematical representation and questionner of self confidence. Data analysis used the Manova. The result of data analysis show that ability of mathematical representation and self confidence using the reciprocal teaching model with the heuristik krulik rudnick strategy. The effectiveness of using the reciprocal teaching model with the heuristik krulik rudnick strategy is more effective on the ability of mathematical representation and self confidenc, shown from the effect size obtained which is included in the high category.
\end{abstract}

Keywords: reciprocal teaching, heuristik krulik rudnick, mathematical representation, self confidence 


\section{PENDAHULUAN}

Matematika merupakan ilmu yeng bersifat universal dan menunjang berbagai bidang ilmu yang lain (Septian, Komala, A, \& Komara, 2019). Matematika merupakan mata pelajaran yang sangat penting untuk dipelajari serta dipahami oleh seluruh peserta didik, begitu pentingnya matematika di bidang ilmu pengetahuan, pembelajaran matematika dimasukkan ke dalam semua jenjang pendidikan di Indonesia dimulai dari sekolah dasar sampai perguruan tinggi (Zuliyanti \& Pujiastuti, 2020).

Berbagai kemampuan yang harus dimiliki oleh siswa salah satunya adalah kemampuan representasi (A. Septian, Darhim, \& Prabawanto, 2020). Kemampuan representasi merupakan kemampuan menyajikan gagasan matematika seperti ide-ide matematis atau penerjemah dari masalah yang diberikan kedalam interpretasi berupa persamaan matematis, bentuk gambar ataupun kata-kata (Misel \& Suwangsih, 2016).

National Council of Teacher of Mathematics (NCTM) mengungkapkan bahwa terdapat lima standar pada pembelajaran matematika yang wajib untuk siswa miliki yaitu: pemecahan masalah (problem solving), penalaran dan pembuktian (reasoning and proof), komunikasi (comunication), koneksi (conection), serta representasi (representation) (Deswantar et al, 2020). Salah satu hal yang harus dimiliki siswa yang mengacu kepada Kurikulum Nasional Tahun 2013, pada kompetensi inti tiga dan empat yaitu kemampuan menyaji atau representasi (Kadir et al, 2019).

Kemampuan representasi adalah kemampuan yang sangat penting yang harus dimiliki oleh siswa dalam mempelajari matematika, namun kenyataannya kemampuan representasi matematis di Indonesia cenderung belum sesuai harapan (Risdianti, Kartono, \& Masrukan, 2019). Rendahnya kemampuan representasi matematika dapat dilihat pada survei TIMSS (Trend in Mathematics and Science Study) dan PISA (Programme for International Student Assesment). Dalam survei TIMSS 2015 Indonesia berada diperingkat 44 dari 49 negara dengan skor 379. Tingkat kemampuan representasi tentang kemampuan peserta didik secara internasional tersebut adalah standar mahir 625, standar tinggi 550, standar menengah 475, dan standar rendah 400 (Hadi \& Novaliyosi, 2019).

Upaya memecahkan permasalahan yang dihadapi yaitu mengembangan kecapakapan matematika peserta didik akan keyakainan terhadap kemampuannya akan terhindar dari cemas dan ragu (Muslimah et al, 2021). Dalam kemampuan representasi terdapat aspek psikologis yang ikut serta memberikan keberhasilan terhadap seseorang agar mampu menyelesaikan tugasnya dengan baik Aspek psikologi tersebut adalah self confidence. 
Berdasarkan informasi yang diperoleh dari hasil wawancara yang telah dilakukan terhadap guru mata pelajaran matematika kelas VIII di SMP Negeri 7 Krui, beliau mengatakan bahwa kemampuan representasi matematika dan self confidence peserta didik tergolong rendah serta partisipasi peserta didik dalam mengemukakan pendapat dalam pelajaran matematika masih kurang.

Siswa mampu sukses dalam belajar matematika jika mereka memiliki self confidence yang baik. Sehingga self confidence dapat mendukung motivasi serta kesuksesan siswa dalam belajar karena siswa akan cenderung memperjuangkan masalah matematika yang ia hadapi untuk diselesaikan dengan menggunakan solusi terbaik (Nuryanti, Saepudin, Hutajulu, \& Herdiana, 2019; Rizkiani \& Septian, 2019). Selanjutnya, Walgio berpendapat bahwa dengan menciptkan suasan kelas yang demokratis, yaitu siswa dilatih agar mampu mengemukan pendapat, berpikir mandiri dan diberi rasa aman ini merupakan salah satu cara untuk menumbuhkan self confidence pada siswa (Purwansih, 2015). Guru harus mampu menciptkan suasana pembelajaran yang mendukung siswa agar memiliki self confidence serta kemampuan representasi matematika yang baik. Pemilihan model serta strategi pembelajaran dikelas memiliki pengaruh pada aktivitas belajar. Keefektifan pembelajaran juga dipengaruhi oleh pemilihan strategi dan model pembelajaran yang kurang tepat.

Berdasarkan dari hasil pengamatan dan wawancara terhadap salah satu guru matematika ketika pembelajaran matematika diperoleh informasi bahwa self confidence peserta didik masih tegolong rendah, dimana ketika pembelajaran matematika berlangsung peserta didik merasa takut untuk mempresentasikan hasil diskusi di depan kelas serta takut dalam menjawab pertanyaan yang diberikan oleh guru. Rendahnya kemampuan representasi matematika dan self confidence peserta didik dan pentingnya kemampuan representasi dan self confidence bagi peserta didik maka diperlukan adanya model yang sesuai dalam upaya meningkatkan kemampuan representasi matematika dan self confidence. Penggunaan model yang tepat dapat mempengaruhi keberhasilan peserta didik dalam proses pembelajaran, dengan memilih model pembelajaran yang tepat maka siswa dapat untuk memaksimalkan kemampuan representasinya. Alternatif model pembelajaran yang dapat memberikan kesempatan kepada siswa untuk menggali informasi dengan cara bertanya serta mengklarifikasi informasi-informasi yang diperoleh siswa. Sehingga diharapkan siswa dapat memprediksi solusi dari masalah-masalah yang mereka temukan. Salah satu model pembelajaran yang memberikan kesempatan tersebut adalah model pembelajaran reciprocal teaching (Artiah \& Untarti, 2017). 
Reciprocal teaching adalah suatu model pembelajaran yang mengajarkan kepada siswa tentang empat strategi kognitif yaitu membuat rangkuman (summarizing), membuat pertanyaan (questioning), mengklarifikasi (clarifying), dan memprediksi (predicting) yang dilakukan siswa secara berkelompok agar siswa dapat memahami suatu materi pelajaran dengan baik dan juga dapat merepresentasi kan ide atau pendapatnya (Astriani, 2017). Dalam berkelompok self confidence peserta didik akan dilatih.

Seperti yang sudah dikatakan sebelumnya, keefektifan dalam belajar juga dipengaruhi oleh pemilihan strategi dan model pembelajaran yang kurang tepat saat pembelajaran. Untuk mewujudkan belajar yang efektif maka guru hendaknya membentuk siswa agar lebih memiliki kepercayaan diri dalam mengikuti strategi pembelajaran yang diterapkan, yang kemudian dapat menjadikan siswa aktif dalam proses pembelajaran (Rohmah, Septian, \& Inayah, 2020). Salah satu alternatif strategi pembelajaran yang mendukung meningkatkan kemampuan representasi matematika adalah strategi heuristik krulik rudnick. Krulik dan Rudnick mengatakan bahwa terdapat 5 langkah pembelajaran dalam strategi heuristik krulik rudnick yaitu: membaca dan berpikir (read and think), eksplorasi dan merencanakan (explore and plan), memilih strategi (select a strategy), mencari sebuah jawaban (find and answer), refleksi dan mengembangkan (reflect and extand) (Kadir et al, 2019).

Penelitian yang relevan dengan penelitian ini adalah penelitian yang dilakukan oleh Wiji Astuti yaitu dengan judul "pengaruh model pembelajaran reciprocal teaching terhadap kemampuan representasi matematis siswa" (Astuti,2018). Pembaharuan penelitian ini dengan penelitian yang dilakukan oleh Wiji Astuti yaitu terdapat pada model pembelajaran ditambahkan dengan strategi heuristik krulik rudnick sebagai variabel bebas serta pada penelitian ini variabel terikatnya tidak hanya satu tetapi terdapat dua variabel terikat, yaitu salah satu variabel terikat adalah self confidence, serta pembaharuan penelitian ini dengan penelitian sebelumnya yaitu pada penelitian sebelumnya hanya untuk mengetahui pengaruh model pembelajaran pada penelitian ini adalah untuk mengetahui seberapa besar pengaruh model pembelajaran yaitu dengan menggunakan rumus effect size.

Berdasarkan permasalahan yang sudah dijelaskan sebelumnya dan melihat penelitian terdahulu, tujuan penelitian ini adalah untuk mengetahui efektivitas penggunaan model pembelajaran reciprocal teaching dengan strategi heuristik krulik rudnick terhadap kemampuan representasi matematika dan self confidence. 


\section{METODE PENELITIAN}

Penelitian ini merupakan penelitian kuantitatif karena data-data yang didapat dan dikumpulkan berupa angka-angka serta proses pengolahan data dan pengujian hipotesis menggunakan analisis statistik dengan jenis penelitian eksperimen semu (quasi eksperimen). Populasi penelitian yaitu seluruh peserta didik kelas VIII SMP Negeri 7 Krui. Teknik sampling yang digunakan adalah cluster random sampling. Sampel terdiri dari 2 kelas yaitu kelas VIII B yang menerapkan model reciprocal teaching dengan strategi heuristik krulik rudnick dan kelas VIII A menerapkan model pembelajaran direct instruction.

Pengumpulan data yang digunakan adalah tes, dan angket. Tes kemampuan representasi matematika dan angket self confidence disesuaikan dengan indikator. Indikator representasi matematika adalah representasi verbal, representasi gambar, dan representasi simbolik (Villages et al. 2009). Indikator self confidence adalah percaya kemampuan diri sendiri, bertindak mandiri dalam mengambil keputusan, memiliki konsep diri yang positif, dan berani mengungkapkan pendapat (Rosdianti et al. 2019). Soal yang diberikan berbentuk essay berjumlah 5 soal dan angket yang diberikan berjumlah 23 penyataan yang terdiri dari item positif dan negatif disetiap indikator.

Instrumen tes dan angket dilakukan uji validitas dan reliabiltas. Uji validitas dilakukan dengan teknik korelasi product moment (Susanto et al. 2015). Uji reliabilitas dilakukan dengan rumus koefisien cronbach alpha (Rinaldi et al, 2021). Setelah instrumen tes dan angket dinyatakan valid oleh dosen dan guru, instrumen tersebut diuji cobakan di luar sampel penelitian yaitu pada kelas IX A. Kedua uji tersebut menghasilkan soal valid dan reliabel serta angket valid dan reliabel.

Teknik analisis data menggunkan uji prasyarat (uji normalitas dan uji homogenitas) dan uji hipotesis (uji Manova). Uji normalitas digunakan untuk mengetahui apakah data berdistribusi normal atau tidak sedangkan uji homogenitas untuk mengetahui apakah data yang diteliti homogen atau tidak. Uji prasyarat (uji normalitas dan uji homogenitas) menggunakan bantuan SPSS 20 dengan taraf signifikan 5\% atau 0,05. Setelah uji prasyarat terpenuhi maka dilanjutkan dengan uji hipotesis menggunakan Uji Manova (Multivariate analysis of variance) dengan bantuan program SPSS 20. Uji tersebut dilakukan guna mengetahui pengaruh model reciprocal teaching dengan strategi heuristik krulik rudnick terhadap kemampuan representasi dan self confidence. Keefektifan model reciprocal teaching dengan strategi heuristik krulik rudnick diuji dengan effect size yang merupakan ukuran mengenai besarnya efek pada suatu variabel pada variabel lain (Siregar et al, 2016). 


\section{HASIL DAN PEMBAHASAN}

Setelah dilakukan proses pembelajaran kemudian dilakukan evaluasi yaitu post-test sebagai pengumpulan data hasil penelitian guna mengetahui kemampuan representasi matematika dan untuk mengetahui self confidence peserta didik melakukan pengisian pada angket yang didalamnya memuat item positif dan negatif pada setiap indikator, sehingga diperoleh $X_{\max }$ (nilai tertinggi) dan $X_{\min }$ (nilai terendah) pada masing-masing kelas yaitu kelas yang menerapkan model reciprocal teaching dan kelas yang menerapkan model direct instruction. Selanjutnya diperoleh $\bar{X}$ (rataan), $M_{e}$ (median), $M_{o}$ (Modus) serta ukuran varians kelompok yaitu $R$ (jangkauan) dan $S D$ (simpangan baku), yang kemudian data tersebut disajikan dalam tabel berikut.

Tabel 1. Rangkuman Deskripsi Data Amatan Post-Test kemampuan Representasi Matematika

\begin{tabular}{|c|c|c|c|c|c|c|c|}
\hline \multirow[t]{2}{*}{ Kelas } & \multirow[t]{2}{*}{$X_{\max }$} & \multirow[t]{2}{*}{$X_{\min }$} & \multicolumn{3}{|c|}{$\begin{array}{l}\text { Ukuran Tendensi } \\
\text { Sentral }\end{array}$} & \multicolumn{2}{|c|}{$\begin{array}{l}\text { Ukuran Variansi } \\
\text { Kelompok }\end{array}$} \\
\hline & & & $\bar{x}$ & $M_{o}$ & $M_{\mathrm{e}}$ & $\mathrm{R}$ & SD \\
\hline $\begin{array}{l}\text { Model Reciprocal Teaching dengan } \\
\text { Strategi Heuristik Krulik Rudnick }\end{array}$ & 95 & 55 & 78,93 & 75 & 80 & 40 & 9,56 \\
\hline Model Direct Instruction & 85 & 45 & 66,61 & 65 & 65 & 40 & 11,06 \\
\hline
\end{tabular}

Berdasarkan tabel 1 menunjukkan bahwa hasil posttes kemampuan representasi matematika pada kelas yang menerapkan model reciprocal teaching dengan strategi heuristik krulik rudnick lebih besar dari hasil posttes pada kelas yang menerapkan model direct instruction.

Tabel 2. Rangkuman Deskripsi Data Amatan Angket self Confidence

\begin{tabular}{lccccccc}
\hline \multirow{2}{*}{ Kelas } & \multirow{2}{*}{$X_{\max }$} & $X_{\min }$ & \multicolumn{3}{c}{$\begin{array}{c}\text { Ukuran Tendensi } \\
\text { Sentral }\end{array}$} & \multicolumn{2}{c}{$\begin{array}{c}\text { Ukuran Variansi } \\
\text { Kelompok }\end{array}$} \\
\cline { 4 - 9 } & 88 & 52 & 71,07 & 68 & 72 & 36 & 9,17 \\
\hline $\begin{array}{l}\text { Model Reciprocal Teaching } \\
\text { dengan Strategi Heuristik Krulik }\end{array}$ & & & & & & & \\
$\begin{array}{l}\text { Rudnick } \\
\text { Model Direct Instruction }\end{array}$ & 77 & 45 & 62,32 & 60 & 61,5 & 32 & 8,37 \\
\hline
\end{tabular}

Berdasarkan tabel 2 menunjukkan bahwa hasil angket self confidence pada kelas yang menerapkan model reciprocal teaching dengan strategi heuristik krulik rudnick memiliki nilai rata-rata lebih besar dari hasil angket self confidence pada kelas yang menerapkan model direct instruction.

Hasil perhitungan uji normalitas kemampuan representasi matematika dan self confidence seperti yang disajikan pada tabel 3 dan tabel 4 berikut. 
Tabel 3. Rangkuman Hasil Uji Normalitas Kemampuan Representasi

\begin{tabular}{|c|c|c|c|c|}
\hline No & Kelas & P-Value & Signifikasi & Keputusan \\
\hline 1 & $\begin{array}{l}\text { Model Reciprocal Teaching dengan } \\
\text { Strategi Heuristik Krulik Rudnick }\end{array}$ & 0,200 & 0,05 & Berdistribusi Normal \\
\hline 2 & Model Direct Instruction & 0,200 & 0,05 & Berdistribusi Normal \\
\hline
\end{tabular}

Berdasarkan tabel 3 hasil uji normalitas pada kemampuan representasi matematika peserta didik pada taraf signifikasi $\alpha=0,05$ dapat diambil sebuah kesimpulan bahwa data yang diperoleh dari kelas eksperimen dan kelas kontrol berasal dari populasi yang berdistribusi normal karna sesuai dengan kriteria dimana $p$-value $>\alpha$. Adapun hasil angket self confidence dapat dilihat pada tabel berikut:

Tabel 4. Rangkuman Hasil Uji Normalitas Angket Self Confidence

\begin{tabular}{|c|c|c|c|c|}
\hline No & Kelas & P-Value & Signifikasi & Keputusan \\
\hline 1 & $\begin{array}{l}\text { Model Reciprocal Teaching dengan } \\
\text { Strategi Heuristik Krulik Rudnick }\end{array}$ & 0,191 & 0,05 & Berdistribusi Normal \\
\hline 2 & Model Direct Instruction & 0,200 & 0,05 & Berdistribusi Normal \\
\hline
\end{tabular}

Berdasarkan tabel 4 hasil uji normalitas angket self confidence terlihat hasil tersebut menunjukkan bahwa $p$-value $>\alpha$. sehingga dapat disimpulkan bahwa sampel berasal dari populasi yang berdistribusi normal. Hasil perhitungan uji homogenitas kemampuan representasi matematika dan self confidence disajikan pada tabel 5 dan tabel 6.

Tabel 5. Rangkuman Hasil Uji Normalitas Kemampuan Representasi

\begin{tabular}{cc}
\hline Statistika & Kemampuan Representasi Matematika \\
\hline P-Value & 0,381 \\
Homogenety & $P$-value $>0,05$ \\
Kesimpulan & Homogen \\
\hline
\end{tabular}

Berdasarkan tabel 5 dapat dilihat bahwa data kemampuan representasi matematika berasal dari varians yang sama atau homogen karena sesuai dengan kriteria dimana $p-$ value $=0,381>\alpha=0,05$. Selanjutnya untuk perhitungan uji homogenitas angket self confidence dapat dilihat pada tabel berikut:

Tabel 6. Rangkuman Hasil Uji Homogenitas Angket Self Confidence

\begin{tabular}{cc}
\hline Statistika & Kemampuan Representasi Matematika \\
\hline P-Value & 0,743 \\
Homogenety & $P$-value $>0,05$ \\
Kesimpulan & Homogen \\
\hline
\end{tabular}

Berdasarkan tabel 6 hasil uji homogenitas angket self confidence terlihat hasil tersebut menunjukkan bahwa $p$-value $>\alpha$, maka sampel berasal dari populasi yang 
homogen. Setelah diperoleh data berdistribusi normal dan berasal dari populasi yang homogen maka selanjutnya dilakukan uji hipotesis dengan menggunakan uji Manova. Uji Manova dihitung dengan bantuan SPSS 20. Uji yang pertama dilakukan adalah Test of Between Subject-Effect atau uji pengaruh antar subjek/variabel. Hasil dari Test of Between Subject-Effect disajikan dalam tabel 7.

Tabel 7. Test of Between Subject-Effect

\begin{tabular}{cccc}
\hline Hipotesis Manova & Kemampuan & P-Value & Keputusan \\
\hline $\begin{array}{c}\text { Model Pembelajaran Reciprocal } \\
\text { Teaching dengan Strategi Heuristik }\end{array}$ & Representasi Matematika & 0,000 & $H_{0 \mathrm{a}}$ ditolak \\
Krulik Rudnick & Self Confidence & 0,000 & $H_{0 b}$ ditolak
\end{tabular}

Berdasarkan tabel 7 dapat dilihat bahwa kemampuan representasi matematika diperoleh p-value yaitu sebesar 0,000 dengan derajat angka signifikasi yang dipakai yaitu 0,05. Hal tersebut menunjukkan bahwa p-value $<0,05$, sehingga $H_{0 a}$ ditolak dan $H_{1 \mathrm{a}}$ diterima. Kesimpulan yaitu terdapat pengaruh model pembelajaran reciprocal teaching dengan strategi heuristik krulik rudnikc terhadap kemampuan representasi matematika.

Untuk self confidence diperolah diperoleh p-value yaitu sebesar 0,000 dengan derajat angka signifikasi yang dipakai yaitu 0,05. Hal tersebut menunjukkan bahwa p-value $<0,05$, sehingga $H_{0 b}$ ditolak dan $H_{1 b}$ diterima. Dapat disimpulkan bahwa terdapat pengaruh model pembelajaran reciprocal teaching dengan strategi heuristik krulik rudnic terhadap self confidence peserta didik. Selanjutnya untuk melihat pengaruh model pembelajaran terhadap kemampuan representasi matematika dan self confidence dilakukan uji Multivariate menggunakan bantuan program SPSS 20. Hasil dari uji Multivariate disajikan pada tabel 8.

Tabel 8. Uji Multivariate

\begin{tabular}{|c|c|c|c|}
\hline Pengaruh & & P-Value & Keputusan \\
\hline $\begin{array}{l}\text { Model Pembelajarn Reciprocal Teaching } \\
\text { dengan Strategi Heuristik Krulik Rudnick }\end{array}$ & Wilks' Lamda & 0,000 & $H_{0 a b}$ ditolak \\
\hline
\end{tabular}

Berdasarkan tabel 8 dapat dilihat bahwa wilks' lamda dengan nilai yang diperoleh pvalue sebesar 0,000 dan derajat angka signifikasi yaitu 0,05. Hal ini menunjukkan bahwa pvalue $<0,05$ sehingga $H_{0 a b}$ ditolak dan $H_{1 a b}$ diterima. Sehingga dapat ditarik kesimpulan bahwa terdapat pengaruh model pembelajaran reciprocal teaching dengan strategi heuristik krulik rudnick terhadap kemampuan representasi matematika dan self confidence. 
Selanjutnya untuk mengetahui seberapa besar pengaruh model pembelajaran reciprocal teaching dengan strategi heuristik krulik rudnick terhadap kemampuan representasi dan self confidence, maka digunakan rumus effect size. Hasil perolehan analisis effect size disajikan pada tabel 9 berikut:

Tabel 9. Rangkuman Hasil Effect Size

\begin{tabular}{cccccc}
\hline Kemampuan & Kelas & Rata-rata & Standar Deviasi & Effect Size & Ket \\
\hline Representasi & Eksperimen & 78,93 & 9,56 & 1,2 & Tinggi \\
Matematika & Kontrol & 66,61 & 11,06 & & \\
Self Confidence & Eksperimen & 70,750 & 9 & 1,03 & Tinggi \\
\hline
\end{tabular}

Berdasarkan tabel 9 dapat dilihat bahwa effect size pada kemampuan representasi matematika sebesar 1,2 dan pada self confidence sebesar 1,03. Maka jika dilihat dari interpretasi nilai cohen's masuk pada kategori tinggi.

Hasil kemampuan representasi matematika dan self confidence, analisis data menunjukkan bahwa kemampuan representasi matematika dan self confidence kelas eksperimen lebih baik dibandingkan dengan kelas kontrol. Penerapam model pembelajaran reciprocal teaching dengan strategi heuristik krulik rudnick memberikan respon yang baik pada peserta didik, peserta didik terlihat lebih aktif, termotivasi hal ini disebabkan karena peserta didik dituntut untuk menyelesaikan masalah sehingga peserta didik secara langsung terlibat dalam proses pembelajaran. Sedangkan pada kelas kontrol pesera didik terlihat pasif dan masih mengandalkan penjelasan guru sehingga ketika peserta didik diberikan permasalahan masih banyak peserta didik yang mengalami kesulitan. Hal ini didukung oleh hasil penelitian Artiah dan Reni Untarti menunjukkan bahwa model dengan menerapkan reciprocal teaching kemampuan representasi matematika peserta didik lebih baik karena peserta didik berperan aktif dalam proses pembelajaran dibandingkan dengan kelas yang menerapkan model direct instruction yang mana peserta didik tidak berperan aktif selama proses pembelajaran, peserta didik hanya mendengarkan penjelasan guru sehingga proses pembelajaram terkesan membosankan sehingga banyak peserta didik yang tidak memperhatikan (Artiah \& Untarti, 2017). Kemudian hasil penelitian yang dilakukan Dana Sudana menunjukkan bahwa dengan menerapkan model reciprocal teaching self confidence peserta didik lebih baik karena model pembelajaran reciprocal teaching merupakan salah satu model pembelajaran yang memberikan pengajaran terhadap peserta didik terkait empat strategi kognitif yang dilakukan secara diskusi untuk memahami materi, peserta didik berperan sebagai guru terhadap teman-teman dikelompoknya, sehingga disini peserta didik berperan aktif selama proses pembelajaran, pesera didik lebih berani untuk mengemukan 
pendapat serta mempresentasikan hasil diskusi nya di depan kelas, dibandingkan kelas yang menerapkan model pembelajaran konvensional yang mana proses pembelajaran hanya berpusat pada guru (Sudana, 2017).

\section{KESIMPULAN}

Penelitian ini menunjukkan bahwa model pembelajaran reciprocal teaching dengan strategi heuristik krulik rudnick lebih efektif terhadap kemampuan representasi matematika dan self confidence. Efektivias penggunaan model pembelajaran reciprocal teaching dengan strategi heuristik krulik rudnick lebih efektif terhadap kemampuan representasi matematika dan self confidence ditunjukkan dari effect size yang diperoleh termasuk dalam kategori tinggi, sehingga model reciprocal teaching dengan strategi heuristik krulik rudnick ini memberikan pengaruh yang tinggi terhadap kemampuan representasi matematika dan self confidence.

\section{REFERENSI}

Artiah, \& Untarti, R. (2017). Pengaruh model reciprocal teaching terhadap kemampuan representasi matematis siswa kelas VII SMP Negeri 6 Purwokerto. AlpaMath, 3(1).

Astriani, L. (2017). Pengaruh pembelajaran reciprocal teaching terhadap kemampuan pemahaman konsep matematika ditinjau dari kemampuan awal matematika siswa. Fibonacci, 3(1).

Astuti, W. (2018). Pengaruh model pembelajaran terbalik (reciprocal teaching) terhadap kemampuan representasi matematis siswa. Serang: Program Studi Pendidikan Guru Sekolah Dasar UPI.

Deswantari, E., Setyadi, D., \& Mampouw, H. L. (2020). Representasi matematis siswa dalam memecahkan masalah matematika materi poligon. Jurnal Pendidikan Matematika Raflesia, 05(01).

Hadi, S., \& Novaliyosi. (2019). TIMSS Indonesia (trend in international mathematics and science study). Tasikmalaya: Prosidir Seminar Nasional \& Call for Paper.

Kadir, Musyrifah, E., \& Safitri, R. D. (2019). Pengaruh strategi heuristik krulik rudnick berbasis etnomatematika terhadap kemampuan representasi geometri. AJME, 1(2), $146-155$.

Misel, \& Suwangsih, E. (2016). Penerapan pendekatan matematika relistik untuk meningkatkan kemampuan representasi matematis siswa. Metodi DIdaktik, 10(2).

Muslimah, N., Putra, R. W. Y., \& Maskyur, R. (2021). Pengaruh model pembelajaran student facilitator and explaining (SFAE) untuk meningkatkan kemampuan pemahaman konsep matematis dan self confidence peserta didik. MAJU, 8(1), 49-59.

Nuryanti, S., Saepudin, E., Hutajulu, M., \& Herdiana, H. (2019). Meningkatkan kemampuan komunikasi matematis dan kepercayaan diri siswa SMP dengan menggunakan pendekatan contextual teaching and learning. Prisma, 8(1), 36. https://doi.org/10.35194/jp.v8i1.381

Purwansih, R. (2015). Peningkatan kemampuan pemahaman matematis dan self confidence siswa mts di kota cimahi melalui model pembelajaran inkuiri terbimbing. Didaktik, $9(1), 16-25$. 
Rinaldi, A., Novalia, S. ., \& Syazali, M. (2021). Statistika inferensial untuk ilmu sosial dan pendidikan. PT Penerbit IPB Press.

Risdianti, A., Kartono, K., \& Masrukan, M. (2019). Pengaruh corrective feedback dalam pembelajaran auditory intellectually repetition ( AIR ) pada pencapaian kemampuan representasi matematis siswa. PRISMA, 2, 10-15.

Rizkiani, A., \& Septian, A. (2019). Kemampuan metakognitif siswa smp dalam pembelajaran matematika dengan menggunakan pendekatan realistic mathematics education ( RME ). UNION: Jurnal Pendidikan Matematika, 7(2), 275-284.

Rohmah, W. N., Septian, A., \& Inayah, S. (2020). Analisis kemampuan penalaran matematis materi bangun ruang ditinjau gaya kognitif siswa menengah pertama. PRISMA. https://doi.org/10.35194/jp.v9i2.1043

Rosdianti, I., Alfiyah, N. F., \& Zanthy, L. S. (2019). Analisis kemampuan koneksi matematik dan self confidence siswa SMP melalui model pembelajaran think pair share. Desimal:Jurnal Matematika, 2(3), 289-295.

Septian, A., Darhim, \& Prabawanto, S. (2020). Mathematical representation ability through geogebra-assisted project-based learning models. Journal of Physics: Conference Series. https://doi.org/10.1088/1742-6596/1657/1/012019

Septian, Ari, Komala, E., \& Komara, K. A. (2019). Pembelajaran dengan model creative problem solving (CPS) untuk meningkatkan kemampuan berpikir kreatif matematis siswa. 8(2), 182-190.

Siregar, A., Latifah, S., \& Sari, M. (2016). Efektivitas model pembelajaran CUPs: dampak terhadap kemampuan berpikir tingkat tinggi peserta didik Madrasah Aliyah Mathla'ul Anwar Gisting Lampung. Jurnal Ilmiah Pendidikan Fisika Al-BiRuNi, 05(2), 233-243.

Sudana, D. (2017). Penerapan model pembelajaran reciprocal teaching untuk meningkatkan kemampuan penalaran dan self confidence matematis siswa sma. Bandung: FKIP Universitas Pasundan.

Susanto, H., Rinaldi, A., \& Novalia. (2015). Analisis validitas reabilitas tingkat kesukaran dan daya beda pada butir soal ujian akhir semester ganjil mata pelajaran matematika. Al-Jabar:Jurnal Pendidikan Matematika, 6(2), 203-217.

Villages, J. L., Castro, E., \& Gutierrez, J. (2009). Representations in problem solving: a case study with optimization problems. Electronic Journal of Reseach in Education Psychology, 17(7), 279-306.

Zuliyanti, P., \& Pujiastuti, H. (2020). Model contextual teaching learning (CTL) untuk meningkatkan kemampuan pemecahan masalah matematis siswa SMP. Prisma, 9(1), 98. https://doi.org/10.35194/jp.v9i1.899 